\title{
Perancangan Sistem Pendukung Keputusan Seleksi Penerimaan Beras Sejahtera (Rastra) Pada Kelurahan Tanjung Pinang Jambi
}

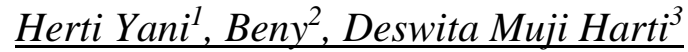 \\ Program Studi Sistem Informasi, STIKOM Dinamika Bangsa, Jambi \\ Jl. Jendral Sudirman, Thehok - Jambi, Telp. 0741-35095/Fax. 0741-35093 \\ Email:adeherti@stikom-db.ac.id ${ }^{1}$,beny@stikom-db.ac.id ${ }^{2}$,deswitamjhnew@gmail.com ${ }^{3}$
}

\begin{abstract}
Kelurahan Tanjung Pinang Jambi is one of the village that have many RT located in Jambi city which selection the receipt of well-being rice still use book in recording and calculation.So that problems occur namely take too long time and a lot of candidate enlisted to gain favor of well-being rice so that the inaccuracy in the selection of revenue caused social jealousy between each candidate. Because of that, this research have purpose to give solution to that happening problems with offer a decision support system of selection the receipt of well-being rice by using PHP programming language, MySQL database, and SMART method where writer make development system with waterfall method and using model approach system unified model language with use case diagram, activity diagram, class diagram and flowchart diagram. So that application can be used by to enable they choose to candidate should get well-being rice for quickly and correctly.
\end{abstract}

Keywords : Decision Support System, SMART, Well-Being Rice

\begin{abstract}
Abstrak
Kelurahan Tanjung Pinang Jambi merupakan salah satu kelurahan yang memiliki banyak RT di Kota Jambi dalam seleksi penerimaan beras sejahtera masih menggunakan buku dalam pencatatan dan perhitungan. Sehingga terjadi permasalahan yaitu membutuhkan waktu yang cukup lama dan banyak calon penerima yang mendaftarkan diri untuk mendapatkan bantuan beras sejahtera sehingga terjadinya ketidaktepatan dalam seleksi penerimaan yang menyebabkan terjadinya kecemburuan sosial antara masing-masing calon penerima. Oleh karena itu, penelitian ini bertujuan memberikan solusi untuk permasalahan yang terjadi dengan menawarkan sistem pendukung keputusan seleksi penerimaan beras sejahtera menggunakan bahasa pemograman PHP, database MySQL, dan metode SMART dimana penulis melakukan pengembangan sistem dengan metode waterfall dan menggunakan pendekatan model sistem unified model language menggunakan usecase diagram, activity diagram, class diagram dan flowchart. Sehingga aplikasi dapat digunakan oleh dapat memberikan kemudahan memilih calon penerima yang layak mendapatkan bantuan beras sejahtera dengan cepat dan tepat.
\end{abstract}

Kata Kunci : Sistem Pendukung Keputusan, SMART, Beras Sejahtera

(C) 2019 Jurnal Ilmiah MEDIA SISFO

\section{Pendahuluan}

Sekarang ini banyaknya masyarakat yang tergolong miskin ataupun kurang mampu di Indonesia. Hal ini membuat pemerintah banyak meluncurkan program bantuan, salah satunya yaitu progam subsidi beras sejahtera untuk mengurangi beban pengeluaran masyarakat berpendapat rendah. Program beras sejahtera atau yang dikenal dengan istilah Rastra merupakan salah satu upaya pemerintah untuk mengurangi beban pengeluaran keluarga berpendapatan rendah dan menjaga pangan masyarakat yang kurang mampu secara ekonomi sehingga diharapkan semua pihak ikut mensukseskan program ini agar bisa dilaksanakan baik dan bermanfaat bagi masyarakat [1].

Kelurahan Tanjung Pinang Jambi merupakan salah satu kelurahan yang memiliki banyak RT di Kota Jambi, yaitu 33 RT dan juga mendapatkan program Rastra dari pemerintah yang disalurkan melalui ketua RT dimasing-masing RT. Seleksi penentuan penerima Rastra yang dilakukan dengan masyarakat mendaftarkan kepada ketua RT dan dicatat ke dalam buku agenda dan kemudian langsung ditentukan 
ketua RT sapa saja yang layak menerima Rastra. Dalam menyeleksi penerima Rastra yang layak cukup sering terjadi permasalahan, yaitu kurang tepatnya distribusi bantuan Rastra karena banyak masyarakat yang melakukan pendaftaran sehingga Kelurahan Tanjung Pinang Jambi mengalami kesulitan dalam melakukan pengolahan data dan memilih penerima yang layak mendapatkan Rastra dan dapat terjadinya kecurangan dalam pemilihan karena hasil dipilih secara subjektif oleh ketua RT sehingga terjadi kecemburuan sosial bagi masyarakat yang seharusnya mendapatkan bantuan Rastra. Permasalahan seperti ini dapat dibantu dengan sistem pendukung keputusan seleksi penerima besar sejahtera (Rastra) menggunakan metode Simple Multy Attribute Rating Techique (SMART) yang memiliki kelebihan dibandingkan metode lain yaitu dapat melakukan penambahan dan pengurangan setiap alternatif, perhitungan yang sederhana dan tidak kompleks, prosedur yang transparan dalam penentuan kriteria, pembobotan dan nilai alternatif serta dapat mulitkriteria.

Adapun tujuan penelitian yang dilakukan oleh penulis, yaitu menganalisis sistem yang sedang berjalan dan merancang sistem pendukung keputusan dalam menyeleksi penerimaan bantuan beras sejahtera (Rastra) pada Kelurahan Tanjug Pinang Jambi dengan menggunakan metode Simple Multy Attribute Rating Techique (SMART), bahasa pemrograman PHP dan database MySQL. Sistem pendukung keputusan menggunakan 5 kriteria yaitu : jenis pekerjaan, jumlah tanggungan, jumlah penghasilan, kepemilikan rumah, luas bangunan rumah. Pemodelan sistem yang akan dirancang menggunakan UML (Unified Modeling Language) yaitu usecase diagram, class diagram, dan activity diagram

\section{Tinjauan Pustaka}

\subsection{Perancangan}

Perancangan secara umum merupakan merumuskan suatu konsep dan ide yang baru atau memodifikasi konsep dan ide yang ada dengan metode-metode yang baru dalam usaha memenuhi kebutuhan manusia. Perancangan menggambarkan rencana umum suatu kegiatan rancangan proyek dan aktivitas-aktivitas khusus yaitu teknik atau metode-metode dalam merancang sesuatu[2]. Perancangan adalah sebuah proses mendefinisikan sesuatu yang dikerjakan dengan menggunakan teknik yang bervariasi serta melibatkan deskripsi mengenai arsitektur serta detail komponen dan juga keterbatasan yang akan dialami dalam proses pengerjaannya [3].

\subsection{Sistem Pendukung Keputusan}

Sistem Pendukung Keputusan (SPK) atau Decision Support System (DSS) merupakan sebuah sistem yang mampu memberikan kemampuan pemecahan masalah maupun kemampuan pengkomunikasian untuk masalah dengan kondisi semi terstruktur dan tak terstruktur. Sistem ini digunakan untuk membantu pengambilan keputusan dalam situasi semi terstruktur dan situasi yang tidak terstruktur, dimana tak seorangpun tahu secara pasti bagaimana keputusan seharusnya dibuat. Sistem Pendukung Keputusan adalah sistem informasi interaktif yang menyediakan informasi, pemodelan, danpemanipulasian data yang digunakan untuk membantu pengambilan keputusan yang semi terstruktur dan situasi yang tidak terstruktur di mana tak seorang pun tau secara pasti bagaimana keptuusan seharusnya dibuat [4]. Sistem pendukung keputusan adalah suatu sistem informasi spesifik yang ditujukan untuk membantu manajemen dalam mengambil keputusan yang berkaitan dengan persoalan yang bersifat semi terstruktur [5].

\subsection{Simple Multi Attribute Rating Technique (SMART)}

SMART merupakan metode pengambilan keputusan multi kriteria yang dikembangkan oleh Edward pada tahun 1977. Teknik pengambilan keputusan multi kriteria ini didasarkan pada teori bahwa setiap alternatif terdiri dari sejumlah kriteria yang memiliki nilai-nilai dan setiap kriteria memiliki bobot yang menggambarkan seberapa penting ia dibandingkan dengan kriteria lain. Pembobotan ini digunakan untuk menilai setiap alternatif agar diperoleh alternatif terbaik. SMART menggunakan linear additive model untuk meramal nilai setiapalternatif. SMART merupakan metode pengambilan keputusan yang fleksibel. SMART lebih banyak digunakan karena kesederhanaanya dalam meresponkebutuhan pembuat keputusan dan caranya menganalisa respon. Analisa yang terlibat adalah transparan sehingga metode ini memberikan pemahaman masalah yang tinggi dan dapat diterima oleh pembuat keputusan [6].

Adapun formulasi metode SMART adalah sebagai berikut: [7]

$S M A R T=\sum_{j=1}^{m} W_{j} u_{i}$ 
Wj adalah nilai pembobotan kriteria ke- $\mathrm{j}$ dari $\mathrm{k}$ kriteria, uij adalah nilai utility alternatif I pada kriteria $\mathrm{j}$. Pemilihan keputusan adalah mengidentifikasi mana dari $\mathrm{n}$ alternatif yang mempunyai nilai fungsi terbesar.

Nilai fungsi ini juga dapat digunakan untuk meranking $\mathrm{n}$ alternative.

Menghitung nilai normalisasi bobot:

$W_{j}=\frac{W_{j}}{\sum_{j=1}^{m} W_{m}}$

$\mathrm{Wj}$ adalah normalisasi bobot kriteria ke- $\mathrm{j}, j$ adalah nilai bobot kriteria ke- $\mathrm{j}$, $\mathrm{k}$ adalah jumlah criteria, $n$ adalah bobot kriteria ke- $\mathrm{n}$.

Menghitung nilai utiliti:

$u_{i j}=f\left(v_{i j}\right)$

Simbol vij adalah nilai kriteria ke- $\mathrm{j}$ untuk alternatif $\mathrm{i}, \mathrm{f}(v i j)$ adalah fungsi kriteria ke- $\mathrm{j}$ untuk alternatif $\mathrm{i}$.

\subsection{Database}

Database atau basis data adalah kumpulan data yang disimpan secara sistematis di dalam komputer yang dapat diolah atau dimanipulasi menggunakan perangkat lunak (program aplikasi) untuk menghasilkan informasi. Database (basis data) adalah tempat menyimpan koleksi data yang terorganisir yang terdiri dari skema, tabel, view, query, store prosedure, dan objek-objek lainnya[8]. Basis data merupakan suatu kumpulan data terhubung yang disimpan secara bersama-sama pada suatu media, yang diorganisasikan berdasarkan sebuah skema atau struktur tertentu, dan dengan software untuk melakukan manipulasi untuk kegunaan tertentu [9].

\subsection{Penelitian Sejenis}

Sukmawati et al, menerapkan sistem penunjang keputusan menggunakan metode SMART dalam menentukan kegiatan ekstra kurikuler yang sesuai dengan perkembangan anak. Sistem akan memberikan masukan apakah siswa dapat mengikuti, dipertimbangkan, atau tidak diikutkan terhadap suatu kegiatan ekstra [10].

Santosa pada penelitiannya menerapkan metode SMART dalam membangung sisteim penunjang keputusan dalam memilih sekolah PAUD. Berdasarkan survey yang disebarkan oleh peneliti, didapatkan kriteria utama dalam pemilihan sekolah PAUD, antara lain biaya, fasilitas, kurikulum, kualitas sekoalah, dan jarak [11].

Yeni dkk membangun sebuah sistem penilaian kinerja dosen teladan dengan menerapkan metode SMART. Kriteria yang digunakan dalam penentuan dosen teladan tersebut antara lain adalah data pengalaman atau masa kerja, bimbingan dan konsultasi, jenjang pendidikan dan jabatan fungsional, penelitian dan pengabdian masyarakat, kehadiran, disiplin, usia, pengalaman atau masa kerja, nilai prestasi kerja, tugas lain-lain diluar tugas utama [12].

\section{Metodologi}

Untuk membantu dalam penyusunan penelitian ini, maka perlu adanya susunan kerangka kerja (frame work) yang jelas tahapan-tahapannya. Kerangka kerja ini merupakan langkah-langkah yang akan dilakukan dalam penyelesaian masalah yang akan dibahas. Adapun kerangka kerja penelitian yang digunakan adalah sebagai berikut :

1. Perumusan Masalah

Pada tahap ini penulis melakukan identifikasi masalah dan yang terjadi dan mencari solusi yang diperlukan untuk pemecahan masalah yang terjadi pada Kelurahan Tanjung Pinang Jambi dalam proses seleksi pemberian beras sejahtera (Rastra) 
2. Studi Literatur

Pada tahap ini dilakukan pencarian landasan-landasan teori yang diperoleh dari berbagai buku, jurnal dan internetmengenai perancangan sistem, sistem pendukung keputusan, SMART, database, use case diagram, activity diagram, class diagram,flowchart, HTML, PHP, MySQL, Dreamweaver CS 5 dan XAMPP untuk melengkapi pembendaharaan konsep dan teori, sehingga memiliki landasan dan keilmuan yang baik dan sesuai.

3. Pengumpulan Data

Dalam penelitian ini penulis menggunakan 3 metode pengumpulan data, antara lain :

a. Wawancara (Interview)

Metode pengumpulan data yang digunakan oleh peneliti secara tatap muka antara peneliti dengan responden untuk mendapatkan suatu informasi secara lisan dengan tujuan untuk memperoleh keterangan - keterangan yang akurat, dapat dipercaya, dan bertanggung jawab terhadap kebenaran fakta mengenai hal - hal yang berkaitan dengan masalah yang di angkat. Peneliti melakukan wawancara pada kepala Kelurahan Tanjung Pinang Jambi

b. Pengamatan Langsung (Observation)

Penulis melakukan pengamatan langsung terhadap proses seleksi penerimaan bantuan beras sejahtera (Rastra) tersebut sehingga penulis dapat memahami prosesyang sedang berjalanpada Kelurahan Tanjung Pinang Jambi.

c. Analisis Dokumen

Penulis mencari dan mempelajari dokumen yang didapat dari Kelurahan Tanjung Pinang Jambi, yaitu laporan calon penerima bantuan beras sejahtera (Rastra) yang digunakan untuk penentuan penerimaan beasiswa siswa miskinsehingga memudahkan peneliti memahami sistem yang akan dirancang untuk sistem pendukung keputusan.

4. Analisis Sistem

Pada tahap ini penulis menganalisis sistem yang sedang berjalan Kelurahan Tanjung Pinang Jambi dan memberikan solusi terhadap masalah yang terjadi yaitu dengan merancang sistem pendukung keputusan penerima beras sejahtera (Rastra) dengan metode Simple Multy Attribute Rating Techique (SMART)menggunakan bahasa pemograman PHP.

5. Pengembangan Sistem

Pada tahap ini, penulis melakukan pengembangan sistem dengan metode waterfall, karena metode tersebut pengaplikasiannya lebih sistematis dan lebih efektif dalam pembuatan sistem informasi.

6. Penulisan Hasil Penelitian

Pada tahap ini penulis membuat laporan dari tugas akhir yang berjudul "Perancangan Sistem Pendukung Keputusan Seleksi Penerimaan Beras Sejahtera (Rastra) Pada Kelurahan Tanjung Pinang Jambi". Dimana pembuatan laporan ini membuat rancangan sistem seperti use case diagram, activity diagram, class diagram, flowchart, perancangan input dan output, dan perancangan struktur data serta membuat aplikasi sistem pendukung keputusan menggunakan PHP dan MySQLsehingga dapat memecahkan masalah yang terjadi.

Penulis menggunakan model air terjun (waterfall) dalam tahap pengembangan sistem dikarenakan pengaplikasiannya mudah dan sistematik.

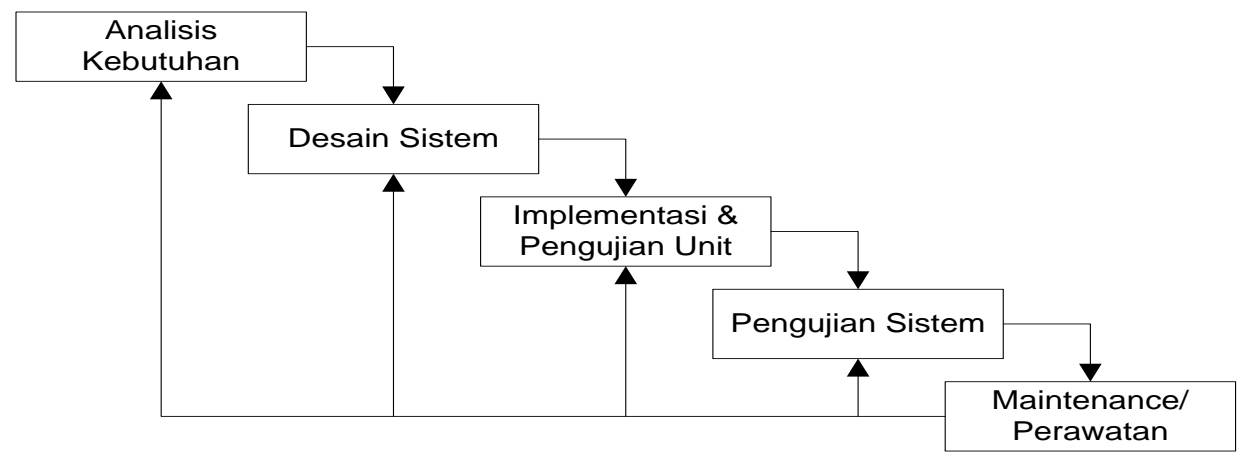

Gambar 1. Model Waterfall 
Adapun penjelasan dari metode pengembangan sistem yang terdapat pada gambar 1 adalah sebagai berikut :

1. Analisis Kebutuhan

Pada tahap ini peneliti mengindentifikasi permasahan yang terjadi pada Kelurahan Tanjung Pinang Jambi yaitu proses pengolahan data penerimaan beras sejahtera (Rastra) yang membutuhkan waktu cukup lama, dan belum adanya sistem terkomputerisasi yang dapat mengelola data peniliaan dan juga menentukan calon penerima yang layak mendapatkan bantuan beras sejahtera (Rastra)

2. Desain Sistem

Pada tahap ini peneliti melakukan desain sistem untuk memecahkan permasalahan yang terjadi dimana penulis merancang sistem berorientasi objek menggunakan usecase diagram, activity diagram, class diagram, flowchart diagram, perancangan input, perancangan output, dan perancangan struktur data sesuai dengan kebutuhan yang diperlukan.

3. Implementasi dan Pengujian Unit

Dalam Tahap ini merupakan tahap proses yang akan memakan waktu yang cukup lama dan yang paling sulit karena tahap ini berisi coding-coding yang harus dikerjakan oleh pembuat sistem. Semua tidak akan berjalan tanpa adanya tahap coding. Dengan membuat program yang telah dirancang sebelumnya. Dimana penulisan coding menggunakan bahasa pemograman PHP dan database MySQL dengan melakukan pengujian unit setiap coding yang telah dibuat agar tidak terjadi kesalahan dalam penggunaannya.

4. Pengujian Sistem

Pada tahap ini dilakukan pengujian menggunakan metode pengujian white box dimana penulis melakukan pengecekan kode-kode program PHP yang ada dan black box dimana penulis melakukan pengecekan hasil keluaran dari aplikasi dan apabila hasil keluar tidak sesuai atau terjadi kesalahan maka penulis melakukan perbaikan agar hasil keluar dari aplikasi sesuai dengan hasil yang diharapkan.

5. Perawatan / Maintenance

Pada tahap ini dilakukan pemeliharaan software seperti melakukan perbaikan - perbaikan terhadap sistem yang berjalan atau menambahkan fungsi tambahan sesuai dengan keinginan pihak Kelurahan Tanjung Pinang Jambi.

Pada penelitian ini, peneliti hanya melakukan proses pengembangan sistem sampai pada tahap keempat yaitu tahap pengujian sistem karena keterbatasan waktu pekerjaan penelitian.

\section{Hasil dan Pembahasan}

\subsection{Analisis Sistem Baru}

Guna membantu pihak Kelurahan Tanjung Pinang Jambi dalam seleksi penerimaan rastra penulis merancang sistem pendukung keputusan yang dapat memberikan keputusan secara cepat dan valid untuk penerimaan seleksi penerimaan rastra yang dilihat berdasarkan penilaian kriteria yang digunakan dengan metode Simple Multy Attribute Rating Techique (SMART), merancang sistem yang menyediakan tempat penyimpanan data yaitu database menggunakan MySQL yang dapat membantu dalam pengolahan data penilaian calon penerima berdasarkan kriteria yang digunakan sehingga memudahkan untuk mendapatkan laporan-laporan untuk hasil penerima bantuan rastra.

\subsection{Analisis Kriteria Perhitungan Penerimaan Rastra}

Proses awal untuk penentuanseleksi penerimaan beras sejahtera (Rastra)calon penerima dengan metode Simple Multy Attribute Rating Techique (SMART), maka penulis memberikan penjelasan mengenai langkah - langkah dalam pengerjaannya, yaitu :

1. Menentukan kriteria dan bobot yang digunakan

Kriteria dan bobot yang digunakan didapat dari hasil wawancara dengan pihak kepala Kelurahan

Tanjung Pinang Jambi yang akan digunakan untuk melakukan perhitungan penilaian.

Tabel 1. Kriteria

\begin{tabular}{clc}
\hline No. & \multicolumn{1}{c}{ Nama Kriteria } & Bobot Nilai \\
\hline 1. & Jenis pekerjaan (K1) & 8 \\
2. & Jumlah tanggungan(K2) & 9 \\
3. & Jumlah penghasilan (K3) & 9 \\
4. & Kepemilikan rumah (K4) & 7 \\
5. & Luas bangunaan rumah (K5) & 7 \\
\hline
\end{tabular}


2. Menentukan rating penilaian

Dengan adanya kriteria dan bobot yang akan digunakan, langkah selanjutnya adalah menentukan rating penilaian untuk masing-masing kriteria. Yang dimulai untuk rating jenis pekerjaan (K1), yang dapat dilihat pada tabel 2 .

Tabel 2. Rating Penilaian Jenis Pekerjaan (K1)

\begin{tabular}{clc}
\hline No. & \multicolumn{1}{c}{ Rating } & Penilaian \\
\hline 1 & PNS / Pegawai Swata & 1 \\
2 & Wiraswasta / Pedagang & 2 \\
3 & Petani & 3 \\
4 & Buruh & 4 \\
5 & Tidak bekerja & 5 \\
\hline
\end{tabular}

Selanjutnya untuk kriteria jumlah tanggungan (K2) yang dilihat dari jumlah tanggungan anak yang dimiliki, yang dapat dilihat pada tabel 3

Tabel 3. Rating Penilaian Jumlah Tanggungan (K2)

\begin{tabular}{|c|c|c|}
\hline No. & Rating & Penilaian \\
\hline 1 & 0 Anak & 0 \\
\hline 2 & 1 Anak & 1 \\
\hline 3 & 2 Anak & 2 \\
\hline 4 & 3 Anak & 3 \\
\hline 5 & 4 Anak & 4 \\
\hline 6. & $\geq 5$ Anak & 5 \\
\hline
\end{tabular}

Selanjutnya untuk kriteria jumlah penghasilan (K3) yang dilihat dari total penghasilan suami istri setiap bulannya, yang dapat dilihat pada tabel 4

Tabel 4. Rating Penilaian Jumlah Penghasilan (K3)

\begin{tabular}{clc}
\hline No. & \multicolumn{1}{c}{ Rating } & Penilaian \\
\hline 1 & > Rp. 2.500.000 & 1 \\
2 & Rp. 2.000.001 - Rp. 2.500 .000 & 2 \\
3 & Rp. $1.000 .001-$ Rp. 2.000 .000 & 3 \\
4 & Rp. 500.001 - Rp. 1.000 .000 & 4 \\
5 & $\leq$ Rp. 500.000 & 5 \\
\hline
\end{tabular}

Selanjutnya untuk kepemilikan rumah (K4) yang dilihat dari kepemilikan rumah dari calon penerima, yang dapat dilihat pada tabel 5 .

Tabel 5. Rating Penilaian Kepemilikan Rumah (K4)

\begin{tabular}{|c|c|c|}
\hline No. & Rating & Penilaian \\
\hline 1. & Milik Sendiri & 1 \\
\hline 2. & Sewa & 2 \\
\hline 3. & Menumpang & 3 \\
\hline
\end{tabular}

Selanjutnya untuk luas bangunan rumah (K5) yang dilihat dari luas bangunan rumah yang dimiliki, yang dapat dilihat pada tabel 6 .

Tabel 6. Rating Luas Bangunan Rumah (K5)

\begin{tabular}{clc}
\hline No. & \multicolumn{1}{c}{ Rating } & Penilaian \\
\hline 1 & $>100 \mathrm{M}^{2}$ & 1 \\
2 & $100-81 \mathrm{M}^{2}$ & 2 \\
3 & $80-61 \mathrm{M}^{2}$ & 3 \\
4 & $60-41 \mathrm{M}^{2}$ & 4 \\
5 & $\leq 40 \mathrm{M}^{2}$ & 5 \\
\hline
\end{tabular}


3. Melakukan Perhitungan Penilaian

Berikut ini merupakan simulasi perhitungan terhadap penilaian calon penerima untuk seleksi penerimaan beras sejahtera (Rastra)dengan menggunakan metode SMART. Beberapa yang calon penerima yang akan dinilai yang dapat dilihat pada tabel 7

Tabel 7. Penilaian Calon Penerima

\begin{tabular}{clcccccc}
\hline No. & Calon Penerima & K1 & K2 & K3 & K4 & K5 & RT \\
\hline 1 & SR & 2 & 2 & 2 & 1 & 5 & 17 \\
2 & FRM & 1 & 1 & 1 & 1 & 5 & 17 \\
3 & KMS & 2 & 1 & 3 & 2 & 4 & 17 \\
4 & ZA & 1 & 5 & 2 & 1 & 4 & 17 \\
5 & SAH & 2 & 0 & 2 & 1 & 5 & 17 \\
6 & AN & 4 & 0 & 3 & 2 & 4 & 20 \\
7 & SN & 2 & 5 & 1 & 1 & 1 & 20 \\
8 & IMS & 2 & 2 & 3 & 1 & 1 & 20 \\
9 & AT & 4 & 2 & 3 & 2 & 3 & 20 \\
10 & YLH & 4 & 2 & 3 & 3 & 3 & 20 \\
11 & RS & 2 & 0 & 1 & 3 & 5 & 21 \\
12 & SM & 2 & 3 & 1 & 2 & 3 & 21 \\
13 & MAA & 1 & 2 & 2 & 1 & 4 & 21 \\
14 & AHY & 2 & 3 & 1 & 1 & 4 & 21 \\
15 & SMR & 2 & 3 & 2 & 1 & 4 & 21 \\
16 & MN & 1 & 2 & 2 & 3 & 2 & 22 \\
17 & MY & 1 & 1 & 2 & 2 & 4 & 22 \\
18 & NRD & 1 & 1 & 1 & 3 & 4 & 22 \\
19 & MA & 4 & 1 & 3 & 3 & 5 & 22 \\
20 & PAG & 2 & 2 & 3 & 3 & 2 & 22 \\
21 & MY & 2 & 4 & 1 & 1 & 2 & 33 \\
22 & SN & 4 & 2 & 3 & 1 & 4 & 33 \\
23 & SAH & 4 & 3 & 3 & 1 & 5 & 33 \\
24 & MN & 4 & 3 & 3 & 2 & 5 & 33 \\
25 & BDY & 4 & 0 & 3 & 3 & 4 & 33 \\
\hline & Maksimum & 4 & 5 & 3 & 3 & 5 & \\
& Minimum & 1 & 0 & 1 & 1 & 1 & \\
\hline
\end{tabular}

Setelah mendapatkan nilai penilaian calon penerima kemudian kita mendapatkan nilai maksimum dan minimum untuk setiap kriteria. Dan seterusnya yang dapat dilihat pada tabel 7 setelah mendapatkan nilai maksimum dan minimum.

Tabel 8. Tabel Normalisasi Bobot

\begin{tabular}{clcc}
\hline No. & \multicolumn{1}{c}{ Nama Kriteria } & Bobot Nilai & Normalisasi Bobot \\
\hline 1. & Jenis pekerjaan (K1) & 8 & $8 / 40=0.2$ \\
2. & Jumlah tanggungan (K2) & 9 & $9 / 40=0.225$ \\
3. & Jumlah penghasilan (K3) & 9 & $9 / 40=0.225$ \\
4. & Kepemilikan rumah (K4) & 7 & $7 / 40=0.175$ \\
5. & Luas bangunaan rumah (K5) & 7 & $7 / 40=0.175$ \\
& Total Bobot Nilai & 40 & \\
\hline
\end{tabular}

Setelah menghitung normalisasi bobot kemudian kita menghitung matriks utility sebagaimana dapat dilihat di tabel berikut.

Tabel 9. Tabel Utility Matriks

\begin{tabular}{clcccccc}
\hline No. & Calon Penerima & K1 & K2 & K3 & K4 & K5 & RT \\
\hline 1 & SR & 0,33 & 0,4 & 0,5 & 0 & 1 & 17 \\
2 & FRM & 0 & 0,2 & 0 & 0 & 1 & 17 \\
3 & KMS & 0,33 & 0,2 & 1 & 0,5 & 0,75 & 17
\end{tabular}




\begin{tabular}{clcccccc}
4 & ZA & 0 & 1 & 0,5 & 0 & 0,75 & 17 \\
5 & SAH & 0,33 & 0 & 0,5 & 0 & 1 & 17 \\
6 & AN & 1 & 0 & 1 & 0,5 & 0,75 & 20 \\
7 & SN & 0,33 & 1 & 0 & 0 & 0 & 20 \\
8 & IMS & 0,33 & 0,4 & 1 & 0 & 0 & 20 \\
9 & AT & 1 & 0,4 & 1 & 0,5 & 0,5 & 20 \\
10 & YLH & 1 & 0,4 & 1 & 1 & 0,5 & 20 \\
11 & RS & 0,33 & 0 & 0 & 1 & 1 & 21 \\
12 & SM & 0,33 & 0,6 & 0 & 0,5 & 0,5 & 21 \\
13 & MAA & 0 & 0,4 & 0,5 & 0 & 0,75 & 21 \\
14 & AHY & 0,33 & 0,6 & 0 & 0 & 0,75 & 21 \\
15 & SMR & 0,33 & 0,6 & 0,5 & 0 & 0,75 & 21 \\
16 & MN & 0 & 0,4 & 0,5 & 1 & 0,25 & 22 \\
17 & MY & 0 & 0,2 & 0,5 & 0,5 & 0,75 & 22 \\
18 & NRD & 0 & 0,2 & 0 & 1 & 0,75 & 22 \\
19 & MA & 1 & 0,2 & 1 & 1 & 1 & 22 \\
20 & PAG & 0,33 & 0,4 & 1 & 1 & 0,25 & 22 \\
21 & MY & 0,33 & 0,8 & 0 & 0 & 0,25 & 33 \\
22 & SN & 1 & 0,4 & 1 & 0 & 0,75 & 33 \\
23 & SAH & 1 & 0,6 & 1 & 0 & 1 & 33 \\
24 & MN & 1 & 0,6 & 1 & 0,5 & 1 & 33 \\
25 & BDY & 1 & 0 & 1 & 1 & 0,75 & 33 \\
\hline
\end{tabular}

Untuk penjelasan perhitungan :
a) Suratno
b) Frimansyah
$K 1=\frac{2-1}{4-1}=0.33$
$K 1=\frac{1-1}{4-1}=0$
$K 2=\frac{2-0}{5-0}=0.4$
$K 2=\frac{1-0}{5-0}=0.2$
$K 3=\frac{2-1}{3-1}=0,25$
$K 3=\frac{1-1}{3-1}=0$
$K 4=\frac{1-1}{3-1}=0$
$K 4=\frac{1-1}{3-1}=0$
$K 5=\frac{5-1}{5-1}=1$
$K 5=\frac{5-1}{5-1}=1$

Dan untuk perhitungan untuk alternatif lainnya memiliki cara yang sama. Setelah menghitung matriks utillity kemudian kita menghitung nilai akhir.

Tabel 10. Tabel Hasil Perhitungan Nilai Akhir

\begin{tabular}{clllllllll}
\hline \multirow{2}{*}{ No. } & Calon & \multirow{2}{*}{ K1 } & \multirow{2}{*}{ K2 } & \multirow{2}{*}{ K3 } & \multirow{2}{*}{ K4 } & K5 & Total & \multirow{2}{*}{ RT } & Hasil \\
\hline 1 & M N & 0,2 & 0,135 & 0,225 & 0,088 & 0,175 & 0,823 & 33 & Terpilih \\
2 & M A & 0,2 & 0,045 & 0,225 & 0,175 & 0,175 & 0,82 & 22 & Terpilih \\
3 & YLH & 0,2 & 0,09 & 0,225 & 0,175 & 0,088 & 0,778 & 20 & Terpilih \\
4 & SAH & 0,2 & 0,135 & 0,225 & 0 & 0,175 & 0,735 & 33 & Terpilih \\
5 & BDY & 0,2 & 0 & 0,225 & 0,175 & 0,131 & 0,731 & 33 & Terpilih \\
6 & AT & 0,2 & 0,09 & 0,225 & 0,088 & 0,088 & 0,691 & 20 & - \\
7 & SN & 0,2 & 0,09 & 0,225 & 0 & 0,131 & 0,646 & 33 & - \\
8 & AN & 0,2 & 0 & 0,225 & 0,088 & 0,131 & 0,644 & 20 & - \\
9 & PAG & 0,066 & 0,09 & 0,225 & 0,175 & 0,044 & 0,6 & 22 & - \\
10 & KML & 0,066 & 0,045 & 0,225 & 0,088 & 0,131 & 0,555 & 17 & - \\
11 & ZA & 0 & 0,225 & 0,113 & 0 & 0,131 & 0,469 & 17 & - \\
12 & SMR & 0,066 & 0,135 & 0,113 & 0 & 0,131 & 0,445 & 21 & - \\
13 & SR & 0,066 & 0,09 & 0,113 & 0 & 0,175 & 0,444 & 17 & -
\end{tabular}




\begin{tabular}{llllllllll}
14 & MN & 0 & 0,09 & 0,113 & 0,175 & 0,044 & 0,422 & 22 & - \\
15 & RS & 0,066 & 0 & 0 & 0,175 & 0,175 & 0,416 & 21 & - \\
16 & IMN & 0,066 & 0,09 & 0,225 & 0 & 0 & 0,381 & 20 & - \\
17 & SS & 0,066 & 0,135 & 0 & 0,088 & 0,088 & 0,377 & 21 & - \\
18 & MY & 0 & 0,045 & 0,113 & 0,088 & 0,131 & 0,377 & 22 & - \\
19 & SAH & 0,066 & 0 & 0,113 & 0 & 0,175 & 0,354 & 17 & - \\
20 & NR & 0 & 0,045 & 0 & 0,175 & 0,131 & 0,351 & 22 & - \\
21 & MAA & 0 & 0,09 & 0,113 & 0 & 0,131 & 0,334 & 21 & - \\
22 & AHY & 0,066 & 0,135 & 0 & 0 & 0,131 & 0,332 & 21 & - \\
23 & SN & 0,066 & 0,225 & 0 & 0 & 0 & 0,291 & 20 & - \\
24 & MY & 0,066 & 0,18 & 0 & 0 & 0,044 & 0,29 & 33 & - \\
25 & FRM & 0 & 0,045 & 0 & 0 & 0,175 & 0,22 & 17 & - \\
\hline
\end{tabular}

Pehitungan nilai akhir :
a) Suratno

$$
\begin{aligned}
& =0.2 * 0.33+0.225 * 0.4+0.225 * 0.5+0.175 * 0+0.175 * 1 \\
& =0.444
\end{aligned}
$$
b) Frimansyah
$=0.2 * 0+0.225 * 0.2+0.225 * 0+0.175 * 0+0.175 * 1$
$=0.22$

Dan untuk perhitungan untuk alternatif lainnya memiliki cara yang sama.

Berdasarkan proses perangkingan diatas dan $20 \%$ dari 25 calon penerima yang mendaftar diri, maka terpilih 5 orang yang layak mendapatkan bantuan beras sejahterah (Rastra) dengan metode Simple Multy Attribute Rating Techique (SMART)

\subsection{Analisis Kebutuhan Sistem}

Use Case Diagram yang dibuat untuk menggambarkan sistem yang baru. Use case diagram memiliki 2 orang aktor yaitu admin dan Kepala Lurah yang memiliki use case yang berbeda. Untuk lebih jelasnya dapat dilihat pada gambar 2

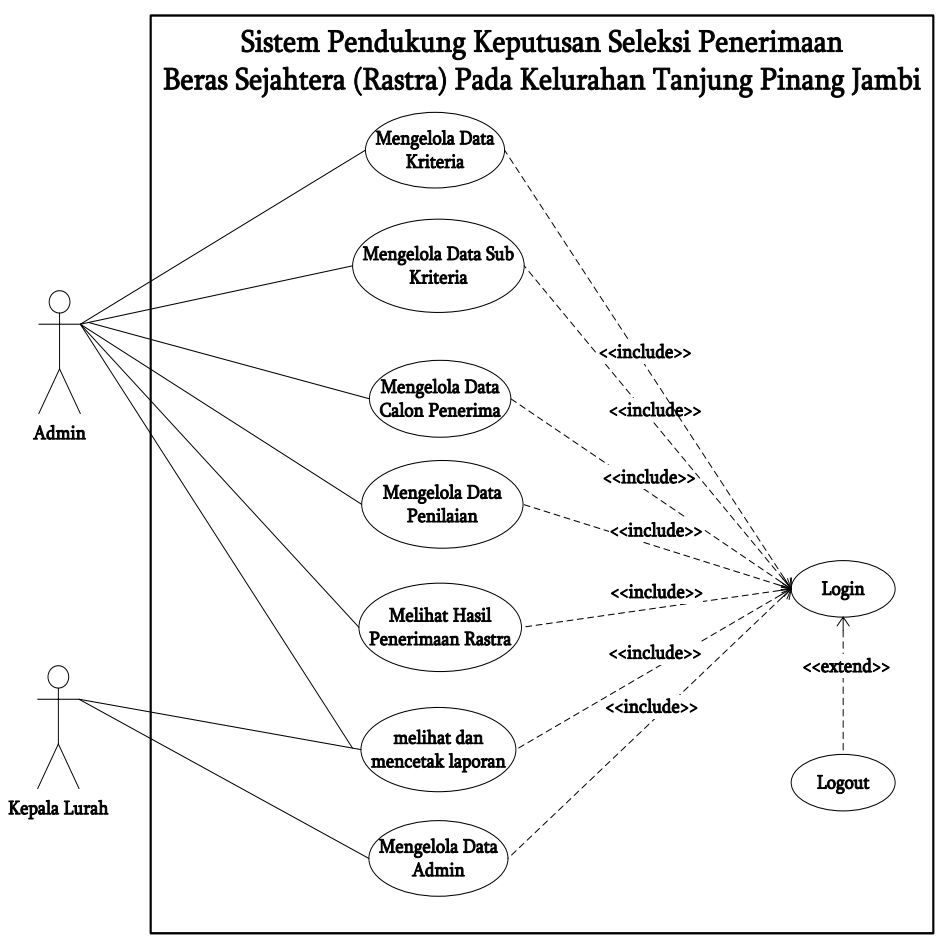

Gambar 2. Use Case Diagram 
Kebutuhan data untuk perangkat lunak yang akan dibuat dapat digambarkan dengan Class Diagram, yang dapat dilihat pada gambar 3

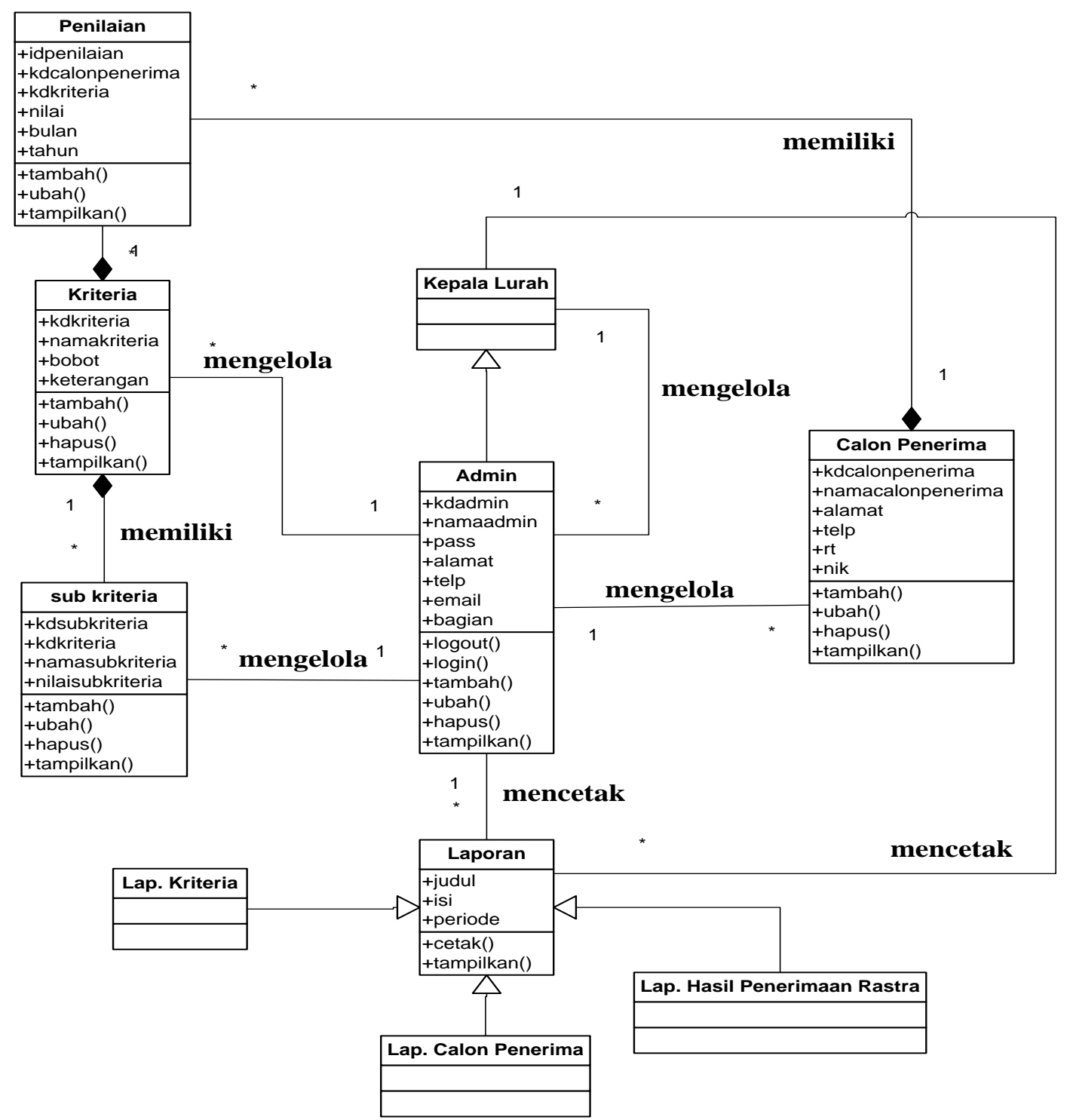

Gambar 3. Class Diagram

\subsection{Implementasi Sistem}

Sistem yang telah dirancang kemudian diimplementasikan dengan fungsi-fungsi sebagai berikut:

1. Halaman Tambah Calon Penerima

Halaman calon penerima menampilkan form yang berisikan field nama calon penerima, alamat lengkap, telepon / hp, rt, nik yang diisi untuk menambah data calon penerima yang baru. 


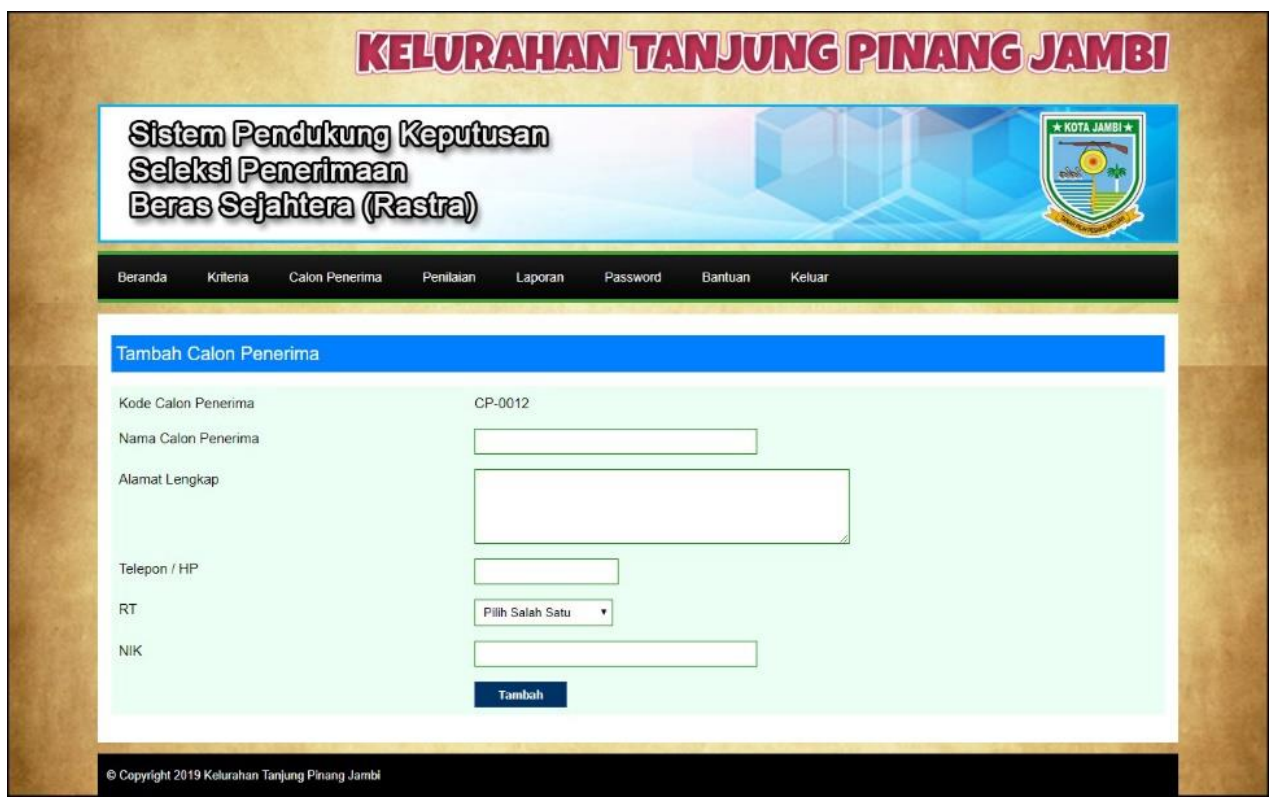

Gambar 4. Halaman Tambah Calon Penerima

2. Halaman Tambah Penilaian

Halaman tambah penilaian menampilkan form yang berisikan field penilaian calon penerima berdasarkan kriteria yang diisi untuk menambah data penilaian yang baru

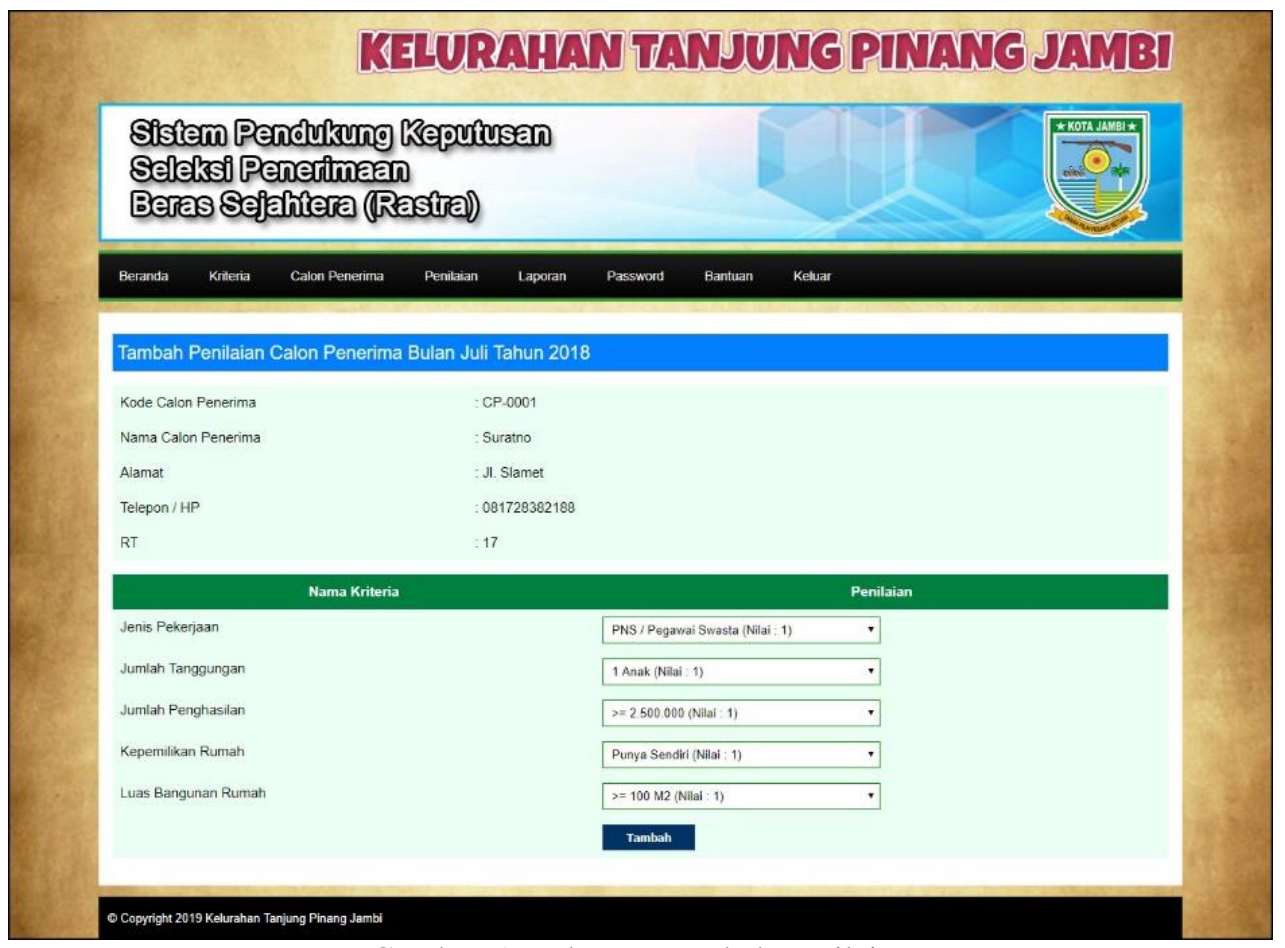

Gambar 5. Halaman Tambah Penilaian

3. Halaman Melihat Hasil Penerima Rastra

Halaman melihat hasil penerima rastra menampilkan data perhitungan penilaian calon penerima berdasarkan kriteria yang digunakan dengan metode SMART dan menampilkan hasil akhir calon penerima yang berhak mendapatkan rastra. 


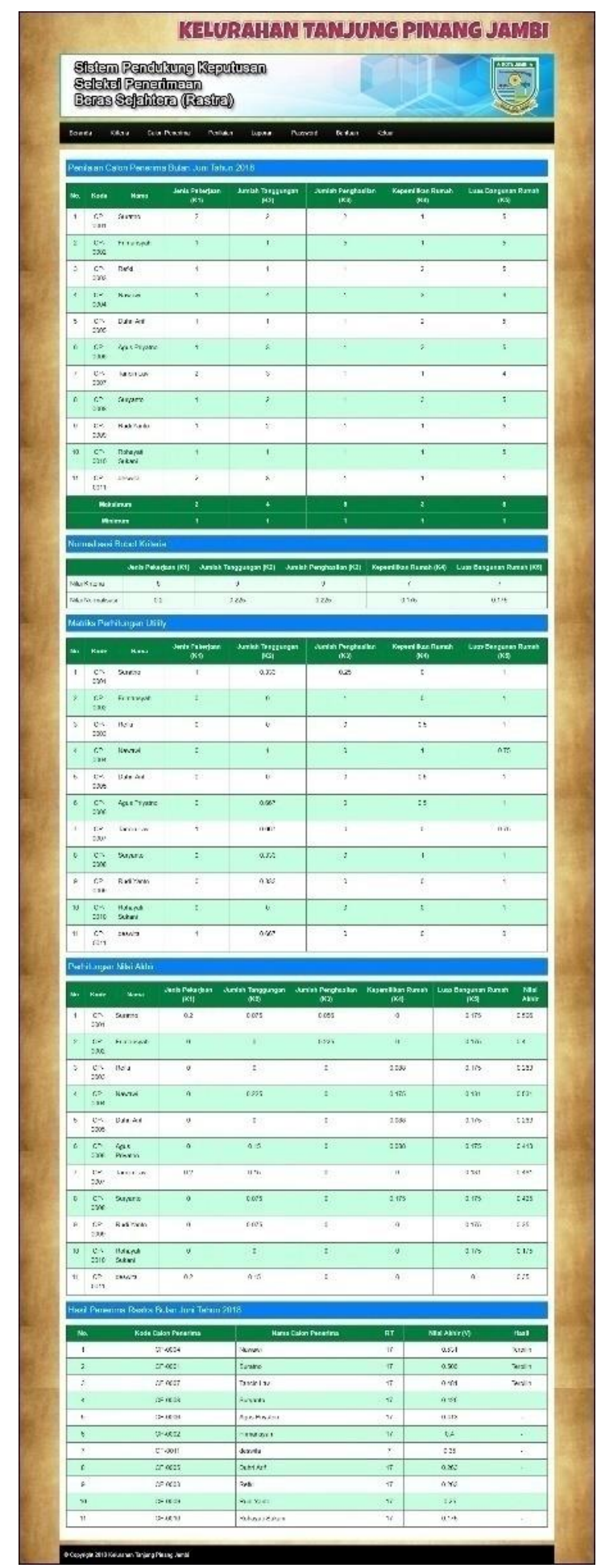

Gambar 6. Halaman Melihat Hasil Penerimaan Rastra

\section{Kesimpulan}

Seleksi penerimaan penerimaan rastra pada Kelurahan Tanjung Pinang Jambi yang masihkurang tepatnya distribusi karena banyak calon penerima yang melakukan pendaftaran bantuan sehingga terjadi kesulitan dalam melakukan pengolahan dan memilih calon penerima yang layak mendapatkan bantuan dan belum adanya sistem terkomputerisasi yang membantu pengolahan data penilaian calon penerima sehingga memakan waktu yang cukup lama dalam menentukan masyarakat yang layak mendapatkan bantuan sehingga hasil penerimaan rastra terkadang terjadi kesalahan ataupun hasil kurang tepat. Perancangan 
sistem pendukung keputusan seleksi penerimaan rastra pada Kelurahan Tanjung Pinang Jambi yang menggunakan bahasa pemograman PHP dan database MySQL bertujuan memberikan hasil penerima beras sejahtera (rastra) lebih cepat dan lebih tepat sehingga hasil yang didapat dapat diterima oleh semua calon penerima dan juga menjadi acuan untuk seleksi berikutnya. Sistem yang dirancang menyediakan fitur-fitur untuk dapat mengelola data admin, mengelola data calon penerima, mengelola data kriteria, mengelola data sub kriteria, mengelola data penilaian dan melihat hasil penerimaanrastra dengan metode Simple Multy Attribute Rating Techique (SMART).

\section{Daftar Pustaka}

[1] B. Rahman, A. Agustian, dan Wahyudi, "Efektifitas dan Perspektif Pelaksanaan Program Beras Sejahtera (RASTRA) dan Bantuan Pangn Non-Tunai (BPNT)," Anal. Kebijak. Pertan., vol. 16, no. 1, pp. 1-18, 2018.

[2] A. S. Rosa, Rekayasa perangkat lunak terstruktur dan berorientasi objek. 2016.

[3] A. Nugroho, Rekayasa perangkat lunak berorientasi objek dengan metode USDP. Penerbit Andi, 2010.

[4] A. Kadir, Pengenalan Sistem Informasi. Percetakan Andi Offset, 2014.

[5] N. Dicky dan D. Sarjon, Multi Criteria Decision Making (MCDM) Pada Sistem Pendukung Keputusan. CV. Budi Utama, 2017.

[6] A. N. Nasution, "Penerapan Metode Simple Multi Attribute Rating Techique Untuk Penentuan Bintang Nararia Bhayangkara (Studi Kasus : Kepolisian Daerah Riau)," Diss. Univ. Islam Negeri Sultan Syarief Kasim Riau, 2013.

[7] Suryanto dan M. Safrizal, "Sistem Pendukung Keputusan Pemilihan Karyawan Teladan Dengan Metode SMART (Simple Multi Attribute Rating Techique)," Univ. Islam Negeri Sultan Syarif Kasim Riau, 2015.

[8] S. Chan, Membuat Aplikasi Database Dengan PowerBuilder 12.6 Dan MySQL. Jakarta: PT. Elex Media Komputindo, 2017.

[9] C. A. Pamungkas, Pengantar Implementasi Basis Data. Yogyakarta: CV. Budi Utama, 2017.

[10] R. Sukmawati, K. Dewi, dan R. Indriati, "Implementasi Metode SMART untuk Mengidentifikasi Perkembangan Anak dalam Mengikuti Ekstra," Nusant. Eng., vol. 3, no. 4, pp. 59-64, 2016.

[11] I. M. A. Santosa, "Perancangan Sistem Pendukung Keputusan Pemilihan Sekolah PAUD Menggunakan Metode SMART," in Konferensi Nasional Sistem \& Informatika, 2017.

[12] Y. Purnamasari, T. H. Pudjiantoro, dan D. Nursantika, "Sistem Penilaian Kinerja Dosen Teladan Menggunakan Metode Simple Multi Attribute Rating Technique (SMART)," J. Teknol. Elektro, vol. 8, no. 1, pp. 16-23, 2017. 